\title{
Prolonged Apnea and Sedation in Premature Babies with the Use of Oral Tramadol
}

\section{Beliz Bilgili*, İbrahim Bozkurt², Pervin Bozkurt² and Fazilet Metin ${ }^{3}$}

${ }^{1}$ Department of Anesthesiology, Marmara University Pendik Teaching and Research Hospital, Istanbul, Turkey ${ }^{2}$ Department of Anesthesiology, Cerrahpaşa Medical Faculty, Kocamustafapaşa, Istanbul, Turkey

${ }^{3}$ Erdem Hospital, Istanbul, Turkey

\begin{abstract}
Clinical studies have shown that premature infants may experience pain in spite of the immaturity of anatomical and functional pathways transmitting nociceptive stimuli [1]. Over the past decade, survival rates for pre-term neonates have increased markedly [2]. The increase in premature birth and survival is provided by $\mathrm{O}_{2}$ therapy and ventilatory management. Oxygen therapy is directly related to Retinopathy of Prematurity (ROP). Screening examination for ROP is a very brief painful procedure and requires long-term follow-up [3]. Although the management of neonatal pain from major single procedures (eg, postoperative pain) has improved significantly, pain management for multiple and repetitive diagnostic and therapeutic procedures (eg, heel lances, suctioning) have not kept pace [2]. Multiple invasive procedures in premature infants caused marked fluctuations in intracranial pressure, possibly leading to early intraventricular haemorrhage and periventricular leucomalacia. Premature infants tend to be more unstable systemically than full term infants of the similar postnatal age, and are more susceptible to apnea and bradycardia [3]. Tramadol was being used in paediatric surgery department even in newborn babies undergoing surgery under general anesthesia, we thought that it could be safe and effective for ROP examination also [4-7].
\end{abstract}

Here we would like to present 3 cases who had heavy sedation and respiratory depression with the use of tramadol $2 \mathrm{mg} / \mathrm{kg}$ (one drop/kg) in premature infants for pain relief and sedation during ROP examination.

Keywords: Apnea; Tramadol; Premature infant

\section{Introduction}

Over the past decade, survival rates for pre-term neonates have increased markedly. However, this improvement has been accompanied by a corresponding increase in the incidence of NICU stays and increased incidence of surgery. Although the management of neonatal pain from major single procedures (eg, postoperative pain) has improved significantly, pain management for multiple and repetitive diagnostic and therapeutic procedures (eg, heel lances, suctioning) have not kept pace [2].

The increase in premature birth and survival is provided by $\mathrm{O}_{2}$ therapy and ventilatory management. Oxygen therapy is directly related to Retinopathy of Prematurity (ROP). Screening examination for ROP is a very brief painful procedure and requires long-term follow-up. In the institution where these incidents took place, the examinations are performed in a special room equipped with anaesthesia machine and an anaesthesiologist stay standby during the examination in order to resuscitate the neonate in emergency because premature infants tend to be more unstable systemically than full term infants of the similar postnatal age, and are more susceptible to apnea and bradycardia [3].

Tramadol is a synthetic opioid with a low affinity for opiate receptors, unlike morphine. Besides mu-agonistic activity, tramadol exerts its effects by inhibition of serotonin and noradrenaline reuptake. It is a potentially useful analgesic drug in pediatrics, compared with morphine when the incidence and magnitude of respiratory depression are considered [4]. Tramadol had been used in paediatric surgery department even in newborn babies undergoing surgery under general anesthesia for last few years in the institution. With this experience and following the reports by Allegaert's study group we thought that it could be safe and effective for ROP examination also [5-7]. Here we would like to present 3 cases who had late heavy sedation and respiratory depression with the use of tramadol $2 \mathrm{mg} / \mathrm{kg}$ (one drop $/ \mathrm{kg}$ ) in premature infants for pain relief and sedation during ROP examination.

\section{Method}

We designed a study to compare the effectiveness of different analgesic methods in premature infants during ROP examination. Tramadol was one of the methods. After the approval of the ethical committe, we started the study, tramadol was given for analgesia in the tramadol group. Twenty premature infants were given tramadol drops $2 \mathrm{mg} / \mathrm{kg}$ at $8: 30$ in the morning while they are in the waiting room and cared by their mothers in their own carrying bags. Their eyes were examined in the following $30 \mathrm{~min}-1 \mathrm{hr}$ period, by the same ophthalmologist after using proparacaine eye drops. The NeonatalInfant Pain Scores (NIPS) were recorded immediately after local anaesthetic application (arrival) and $1 \mathrm{~min}$ after, at Placement of Speculum (PS1) to the first eye, during Retinal Depression (RD1), and repeating the same steps for the other eye (PS2, RD2), 1 min and 2 min (departure) after the procedure has ended. In the mean time, oxygen saturation and heart rate was monitored by $\mathrm{SpO}_{2}$ (Millenia monitor) probe placed to one of the hands. After the examination all babies were kept in the waiting room for final evaluation of sedation levels and respiratory monitoring (watch for apnoea and respiratory rate). The babies coming from home sent back to their home and others coming from NICU's sent back in their incubators. Three babies out of twenty had heavy sedation and apnea 10-18 hours later following tramadol drop usage.

*Corresponding author: Beliz Bilgili, MD, Department of Anesthesiology, Marmara University Pendik Teaching and Research Hospital, Değirmen Sok. No: 5 D: 12 Kozyatağı, İstanbul, Turkey, E-mail: belizbilgili@gmail.com

Received May 15, 2012; Accepted June 26, 2012; Published June 30, 2012

Citation: Bilgili B, Bozkurt I, Bozkurt P, Metin F (2012) Prolonged Apnea and Sedation in Premature Babies with the Use of Oral Tramadol. J Clin Case Rep 2:163. doi:10.4172/2165-7920.1000163

Copyright: (c) 2012 Bilgili B, et al. This is an open-access article distributed under the terms of the Creative Commons Attribution License, which permits unrestricted use, distribution, and reproduction in any medium, provided the original author and source are credited. 


\section{Results}

\section{Case 1}

Baby (EHH) was born at 32 weeks of gestation, with a birth weight of $1.370 \mathrm{~kg}$ and APGAR score of 0 . He had been resuscitated and intubated and admitted to NICU and artificial ventilation was performed and discharged from hospital in one month. The incident occurred when the babies' postconceptual age was 39 weeks (1760 g). He was brought to the hospital from home at 8:00 and given 1 drop of oral tramadol and admitted to the examination room $30 \mathrm{~min}-1 \mathrm{hr}$ after. His NIPS were $0,0,7,7,7,7$, and 0,0 at times arrival, 1 min after, PS1, RD1, PS2, RD2, 1 and 2 min after the procedure consecutively. His NIPS was 0 when he was leaving hospital 2 hours after the procedure and sedation level was as all babies sleeping but arousing when stimulated. His parents took him to their previous private hospital when they observed apnoea after long hours of sleeping (at midnight). According to the report of the neonatalogist in the private hospital (approximately 15 hours after tramadol) the baby was having shallow breathing, frequent apnoea, cyanotic and hypoactive. His reflexes were weak, fontanella normal, temperature $36.1^{\circ} \mathrm{C}$, heart rate $137 / \mathrm{min}$ and blood pressure $58 / 35 \mathrm{mmHg}$. His belly was soft, chest $\mathrm{x}$-ray normal and blood gasses pH 7.30, PCO2 $57 \mathrm{mmHg}$, PO2 $42.9 \mathrm{mmHg}$, bases excess $27.7 \mathrm{mmol} / \mathrm{L}$. He was started CPAP and given antibiotic and fluid replacement $60 \mathrm{ml} / \mathrm{kg}$. Later he had severe apnoeas and generalized tonic convulsion 3 times and developed bradycardia. Four hours after admission he was intubated the baby and initiated SIMV and given phenobarbital. He was found anemic (Hemotocrit level 25\%) and blood transfusion performed. All of his functions, neurologic examination and ultrasound found normal the next day and extubated and stayed in $\mathrm{O}_{2}$ hood another day. He was discharged from the hospital $5^{\text {th }}$ day in perfect status and breast fed.

\section{Case 2}

Baby (ASD) born at 32 weeks of gestation, with a birth weight of $1.460 \mathrm{~kg}$. He had developed neonatal icterus and had been admitted to NICU in a private hospital with the diagnosis of sepsis. He had been discharged from NICU in 7 days. The baby had been examined several times for ROP. The incident took place when her postconceptual age was 37 weeks and weight $2.200 \mathrm{~kg}$. Similar to others she was given 2 drops of oral tramadol when she arrived from home. Her NIPS in the examination room were $0,6,7,7,7,7$, and 0,0 . Her NIPS was 0 when she was leaving hospital 2 hours after the procedure and sleeping but arousing when stimulated. The parents reported that she slept in the rest of the day and while she cannot breast feed, the parents gave her mother's milk very carefully. All the parents of premature infants were thought to feed in such a way previously. Later in the day at 17:00 the family took the baby to the other medical faculty of the University. Her blood counts had revealed severe anemia (Hemoglobin level, $6.6 \mathrm{~g} / \mathrm{dL}$, Hemotocrit 20\%) and blood transfusion was performed. The neonatalogist received the information that the baby was given tramadol by phone call. They decided to observe the baby. The baby had slept until the next day at 15:00 (until 31 hours after tramadol was given) and she was crying whenever heel lancing performed for blood sampling. She was discharged from hospital after 2 days stay. Her laboratory values at discharge were as follows: alkaline phosphatase 799 U/L, AST 127 U/L, LDH 1798 U/L, GT 87 U/L, creatine kinase 2834 U/L, blood glucose-108 mg/dL, hsCRP $0.6 \mathrm{mg} / \mathrm{dL}$ ). She was admitted for ROP examination 2 weeks later and she was given $2 \mathrm{ml}$ of $24 \%$ dextrose for sedation but it was no help.

\section{Case 3}

Baby (HS) born at 32 weeks of gestation and with a birth weight of $1250 \mathrm{~g}$. He had been admitted to NICU in a private hospital due to respiratory distress and prematurity and observed for 1 month. $\mathrm{He}$ was at $37^{\text {th }}$ week of postconceptual age and his weight was $1630 \mathrm{~g}$ when screened for ROP. He was given 1 drop of tramadol and his scores in the examination room were $0,0,6,7,7,0,0$. When he was leaving the hospital he was sleeping with and he didn't have apnoea. Parents reported that he slept whole day and 20 hours after examination they took the baby to their previous hospital. The baby was given $\mathrm{O}_{2}$ and observed there for 48 hours and his laboratory findings were within normal limits (Hematocrit 34\%, Hemoglobin $11.2 \mathrm{mg} / \mathrm{dl}$ ).

\section{Discussion}

After these three cases of heavy sedation and apnea as a result of tramadol usage, we quitted using tramadol drops for pain relief in ROP examination.

Several techniques such as use of local anesthetics, general anesthesia, sedation/ analgesia by sucking sucrose or use of several sedative drugs orally or intravenous drugs are defined for analgesia in babies [8,9, personal discussion Josef Jolzki]. In the search of best pain treatment for these premature babies with no intravenous line, use of oral tramadol was one option. Several reports by Allegeart's group had encouraged the use of tramadol for us. In Allegeart's studies tramadol was administered with IV bolus $1 \mathrm{mg} \mathrm{kg}^{-1}$ and maintenance by infusion of tramadol hydrochloride $0.09 \mathrm{mg} \mathrm{kg}^{-1} \mathrm{~h}^{-1}$ (target concentration of $300 \mathrm{mg} \mathrm{litre}^{-1}$ ) to infants as low as 25 weeks gestational age weeks with no complications in NICU settings for performing pharmacokinetic studies. Allageart et al. [10] observed a lag time of 4 hours in a full term newborn between intravenous administration of tramadol and plasma/cerebrospinal fluid equilibration. In a case report where 100 mg of rectal tramadol administered to a 6 month old infant the CSF concentration of tramadol showed the exactly similar elimination curve as intravenous administration and equilibration between the plasma and central compartment achieved in $17 \mathrm{~h}$ after rectal administration of the drug [11]. In all three cases heavy sedation observed in the early afternoon (more than 4 hours after oral tramadol administration) coincides with the information in the literature. The presence of anemia in two premature infants presented here should have triggered apnea in conjunction with the peak central effects of tramadol. Anemia is also directly related to apnea of prematurity [12].

In the literature it is stated that the premature babies with the high risk of ROP are screened in the NICU by ophthalmologist. In the country where the incidents took place is a huge inhabitant area of 10 million people and in which hundreds of hospitals are located. The eye clinic of the university is a referral centre for screening of ROP. Because the number of babies were high, a special room was designed for this procedure. The babies arriving mostly from home had to be street fit before they leave the examination area and best modes of pain treatment should be provided.

\section{Conclusion}

Although the pharmakinetics of tramadol for premature infants were studied and had been proven safe it should be used when the infants are closely observed and/or monitored in hospital settings. The use of oral tramadol is insecure in premature babies for outpatient sedation and analgesia. 
Citation: Bilgili B, Bozkurt I, Bozkurt P, Metin F (2012) Prolonged Apnea and Sedation in Premature Babies with the Use of Oral Tramadol. J Clin Case Rep 2:163. doi:10.4172/2165-7920.1000163

\section{References}

1. Sammartino M, Bocci MG, Ferro G, Mercurio G, Papacci P, et al. (2003) Efficacy and safety of continuous intravenous infusion of remifentanil in preterm infants undergoing laser therapy in retinopathy of prematurity: clinical experience. Paediatr Anaesth 13: 596-602.

2. Stevens B, Yamada J, Beyene J, Gibbins S, Petryshen P, et al. (2005) Consistent management of repeated procedural pain with sucrose in preterm neonates: Is it effective and safe for repeated use over time? Clin J Pain $21: 543-548$

3. Stevens BJ, Franck LS (2001) Assessment and management of pain in neonates. Paediatr Drugs 3: 539-558.

4. Allegaert K, de Hoon J, Verbesselt R, Devlieger H, Tibboel D (2005) Tramadol concentrations in blood and in cerebrospinal fluid in a neonate. Eur $\mathrm{J}$ Clin Pharmacol 60: 911-913.

5. Allegaert K, Van den Anker JN, Verbesselt R, de Hoon J, Vanhole C, et al. (2005) O-demethylation of tramadol in the first months of life. Eur J Clin Pharmacol 61: 837-842.

6. Allegaert K, Anderson BJ, Verbesselt R, Debeer A, de Hoon J, et al. (2005) Tramadol disposition in the very young: an attempt to assess in vivo cytochrome P-450 2D6 activity. Br J Anaesth 95: 231-239.
7. Allegaert K, Rayyan M, de Hoon J, Tibboel D, Verbesselt R, et al. (2006) Contribution of glucuronidation to tramadol disposition in early neonatal life. Basic Clin Pharmacol Toxicol 98: 110-112.

8. Mitchell A, Stevens B, Mungan N, Johnson W, Lobert S, et al. (2004) Analgesic effects of oral sucrose and pacifier during eye examination for retinopathy of prematurity. Pain Manag Nurs 5: 160-168.

9. Haigh PM, Chiswick ML, O'Donoghue EP (1997) Retinopathy of prematurity: systemic complications associated with different anaesthetic techniques at treatment. Br J Ophthalmol 81: 283-287.

10. Allegaert K, de Hoon J, Verbesselt R, Devlieger H, Tibboel D (2005) Tramado concentrations in blood and in cerebrospinal fluid in a neonate. Eur $\mathrm{J}$ Clin Pharmacol 60: 911-913.

11. Riedel F, von Stockhausen HB (1984) Severe cerebral depression afte intoxication with tramadol in a 6 month-old infant. Eur J Clin Pharmacol 26 : 631-632.

12. Coté CJ, Zaslavsky A, Downes JJ, Kurth CD, Welborn LG, et al. (1995) Postoperative apnea in former preterm infants after inguinal herniorrhaphy: $A$ combined analysis. Anesthesiology 82: 809-822. 